\title{
Pesticide Residue Measurement in Commonly Used Vegetables Using the QuEChERS Method
}

\author{
Waad Hamad AlSaikhan, Saleh A. Almatroodi, Ahmad Almatroudi, Mohammed A. Alsahli, Arshad Husain \\ Rahmani*
}

Waad Hamad AlSaikhan, Saleh A. Almatroodi, Ahmad Almatroudi, Mohammed A. Alsahli, Arshad Husain Rahmani*

Department of Medical Laboratories, College of Applied Medical Sciences, Qassim University, Buraidah 52571, SAUDI ARABIA.

\section{Correspondence}

\section{Arshad Husain Rahmani}

Department of Medical Laboratories, College of Applied Medical Sciences Qassim University, Buraidah 52571, SAUDI ARABIA.

E-mail: ah.rahmani@qu.edu.sa

\section{History}

- Submission Date: 02-09-2020;

- Review completed: 15-10-2020;

- Accepted Date: 26-10-2020.

DOI : 10.5530/pj.2021.13.20

Article Available online

http://www.phcogj.com/v13/i1

\section{Copyright}

(C) 2021 Phcogi.Com. This is an openaccess article distributed under the terms of the Creative Commons Attribution 4.0 International license.

\section{ABSTRACT}

The aim of current study was to measure the pesticide residues level in vegetables in the Unaizah city, Saudi Arabia. A total of 40 samples including tomato, cucumber, zucchini and red pepper were analysed for various types of pesticides using Quick Easy Cheap Effective Rugged and Safe (QuEChERS) method. The results show that $65 \%$ of samples of supermarket and farms contained 14 types of pesticides but pesticides residue level was below the maximum residue levels (MRL) whereas 30\% samples were free from pesticides. A total $05 \%$ of the vegetables samples were found to exceed the maximum residue levels (MRLs). Moreover, the results indicate that the tomato samples with residue $<M R L$ were $100 \%$. A total of $20 \%$ of the zucchini samples were with residue $<M R L$ and $80 \%$ of the red pepper samples were with residue $<M R L$. Cucumber sample from farms showed insecticides were found to exceed the $M R L$ and none of the fungicides detected exceeded the MRL. However, the concentration of acetamiprid was $0.078 \mathrm{mg} \mathrm{kg}^{-1}$ in cucumber was exceeded the maximum residue levels (MRLs) which was $0.03 \mathrm{mg} \mathrm{kg}^{-1}$ and residues of carbofuran that exceeded the MRLs was $0.026 \mathrm{mg} \mathrm{kg} 1$. Acetamiprid was the most commonly detected pesticides and followed by imidacloprid. The results designated that most of the vegetable samples were contaminated with different types of pesticide residues. The high levels of pesticide residues could be a public health problem including pathogenesis because most of the tested vegetables are commonly used as without cooking.

Key words: Vegetables, Maximum residues limit, QuEChERS, GC-MS/MS, LC-MS/MS.

\section{INTRODUCTION}

Vegetables are plants parts such as red pepper, cucumber, tomato, and onions which we eat in various forms. Vegetables provide vitamins, proteins, carbohydrate minerals and various other essential component and such compound plays a significant role in human nutrition and inhibit the pathogenesis of various diseases. Moreover, vegetable are rich source of antioxidant and antioxidant potentiality of vegetables shows pivotal role in health management through scavenging the free radical. Increasing industrial and agricultural uses of heavy metals have led to an exponential increase in the concentration of such materials in soil and water, and then in a range of food sources, resultant in passage to humans through consumption, inhalation, and direct skin contact ${ }^{1,2}$. Pesticides are substances or mixtures of substances that are principally used in agriculture or in public health protection programs in order to protect plants from pests, weeds or diseases, and humans from vector-borne diseases ${ }^{3}$. Besides, pesticides may enter the body through various ways depending on species, metabolic individualities, and susceptibility to toxins ${ }^{4}$. Recent finding evidences that the ability of pesticides to act as endocrine disruptors, causative of various adverse effects related with reproductive and developmental toxicity ${ }^{5-10}$. Moreover, the high level of pesticides causes various types of pathogenesis including abnormality of nerve conductions and renal problem even at short-term exposure whereas long-term exposure causes asthma; depression and anxiety and various types of cancer.

Maximum residue levels [MRLs] are the highest levels of residues probable to be in the food when the pesticide is used according to authorized agricultural practices ${ }^{11}$. The MRLs are set below levels considered to be safe for humans. Thus, maximum residue levels (MRLs) for pesticides have recognized globally, which usually guide to deal with the quantity of pesticides in foodstuffs. Measurement of pesticides level in foodstuffs is essential because high level of pesticides causes pathogenesis. In this context, the use of mass spectrometry, with its information-rich content and clear confirmation, is recommended for monitoring pesticide residues worldwide ${ }^{12-16}$. A routinely used procedure for extracting pesticides is the method 'QuEChERS' (Quick, Easy, Cheap, Effective, Rugged and Safe $)^{17}$. This approach to sample clean-up with simplified and streamlined sample preparation has been recognised for an extensive range of mediums including fruits and vegetables and is now extensively established $^{18}$. The current study aimed to screen the pesticides residues in vegetables samples by using rapid automated screening methods.

\section{MATERIALS AND METHODS}

The study was performed to assess the pesticides residues level in vegetables from different farms

Cite this article: Alsaikhan WH, Almatroodi SA, Almatroudi A, Alsahli MA, Rahmani $A H$. Pesticide Residue Measurement in Commonly Used Vegetables Using the QuEChERS Method. Pharmacog J. 2021;13(1): 142-9. 
and supermarket and it was compared it with the Maximum Residues Level of pesticide according to European Union Pesticides Database. Pesticides level of was measured using Gas chromatography and Liquid chromatography- Mass spectrometry system at Experiment in Food and Environment Laboratory in Unaizah city, Saudi Arabia.

\section{Study sample}

This study was conducted on vegetables samples from different farms and supermarket in Unaizah city. Sample size was 40 vegetables samples obtained from different supermarkets $(n=20)$ and farms $(n=20)$ [Figure 1]. The samples included four types of vegetables such as tomato, zucchini, red pepper and cucumber and sampling was performed as per the general principles and methods of the European Commission (EC) directive $2002 / 63 / \mathrm{EC}^{19}$ for establishing MRLs in food commodities.

\section{Data collection}

The samples were collected in sterile plastic bag labelled with date, location, name of collector and observation was made. Before collection of the samples, gloves and other precautionary measure were taken to avoid the possible contamination of the sample. Samples analysis was conducted in Food and Environment Laboratory in Unaizah, Saudi Arabia by using liquid chromatography-tandem mass spectrometry (LC-MS/MS) and gas chromatography-mass Spectrometry (GC-MS). The extraction and clean-up method was used based on QuEChERS (quick easy cheap effective rugged and safe) sample preparation method for pesticides ${ }^{17}$ and little modification of previously discussed methods ${ }^{20}$.

An aliquot of homogenized sample (18 g) was placed in a tube, and then acetonitrile $(17 \mathrm{ml})$ was added to the sample. Then such mixture
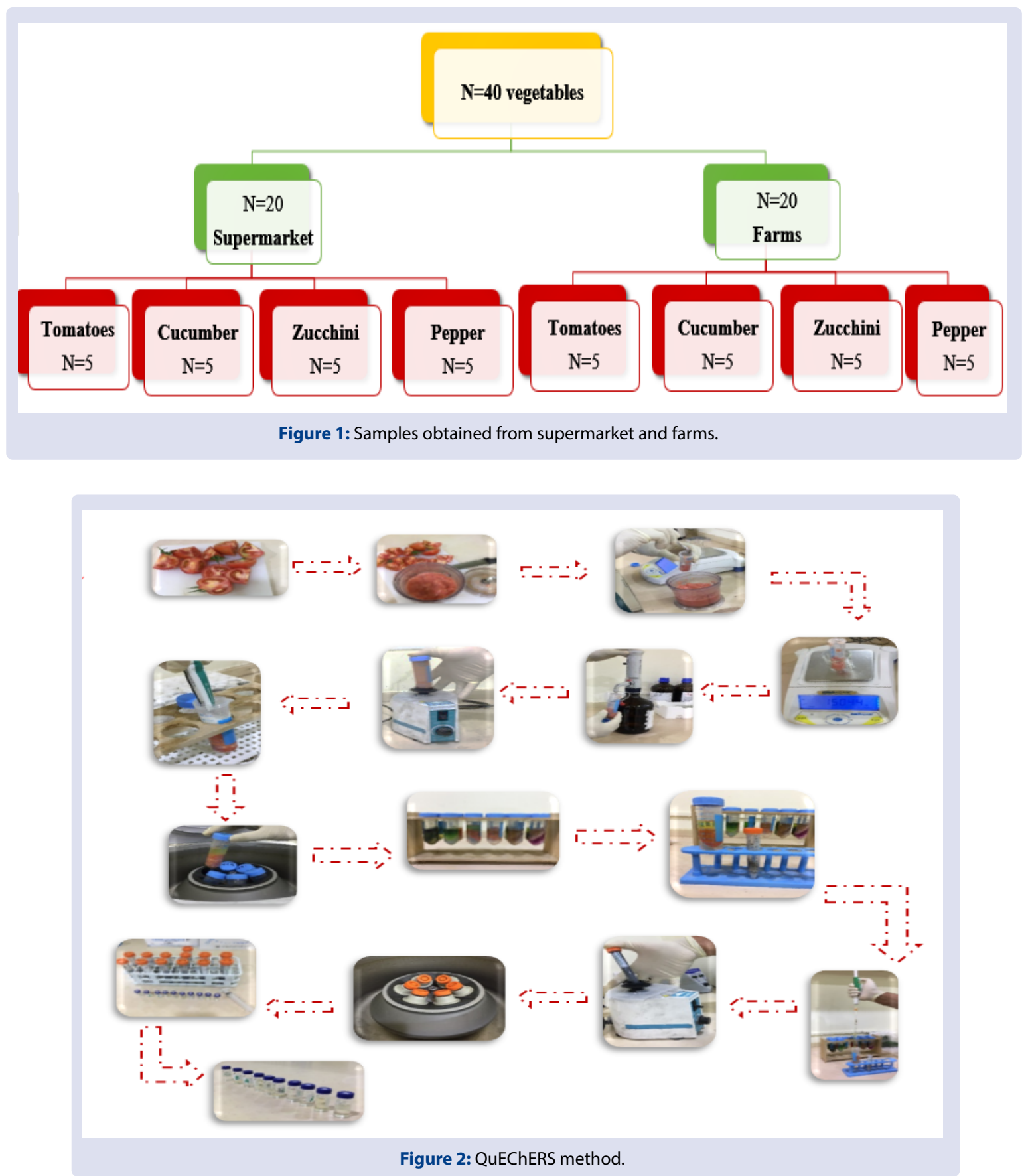
was properly shaken for 1-1.5 minutes and vortex was done for onetwo minute and then magnesium sulfate and sodium acetate were added to the samples. Moreover, sample was then centrifuged, and the supernatant was removed to clean-up the sample. The clean-up of the samples was performed through transferring the supernatant into another fresh tube containing primary and secondary amine and (1200 mg) magnesium sulfate. After agitation and centrifugation, the extract (1-1.5 ml) was used for liquid chromatography-tandem mass spectrometry (LC-MS/MS) analysis and gas chromatography-mass spectrometry (GC-MS/MS) analysis.

Liquid chromatography-mass spectrometry (LC-MS/ MS) and Gas chromatography-mass spectrometry (GC$\mathrm{MS} / \mathrm{MS})$ :

The sample was kept on the rack of the machine (LC-MS/MS) and (GCMS/MS). The chromatography, the automatic needle was injected only 5-10 um from the sample. Between sample and another sample there is a strong liquid detergent used to prevent the all possible contamination. After that, the sample was transported to the mass spectroscopy for identification of various types of pesticides. Every pesticide has such a fingerprint for identification. The pesticides showed as peaks on the system and each pesticide have distinct peak. The mechanism work with MRM Multi-Reaction Monitoring and the after showing the peak, the calculation was conduct based on the standard curve. And then compared the result to the standard curve is it high or low. Then concentration of pesticides was ready to compare with MRLs of European Union Pesticides Database.

\section{Statistical analysis}

The data entered in Microsoft Excel software and analysed using descriptive analysis. All results presented in detail by using tables and graphs.

\section{Ethical Statement}

Ethical approval for this study was obtained from College of Applied Medical Sciences, Qassim University and Departmental Research Review Committee. Permission was taken from Unaizah Municipality to process the samples in the Food and Environment Laboratory.

\section{RESULTS}

Vegetable samples without pesticide residue and with residue below the Maximum residue limits (MRL) and above the (MRL) was compared to the European Union Standards. The results show that the tomato samples with residue < MRL were $100 \%$. $20 \%$ of the pepper samples were without residue and $80 \%$ were with residue $<$ MRL. The cucumber samples without residue were $20 \%$, with residue $<$ MRL were $60 \%$ and with residue $>$ MRL were $20 \%$. A total of $80 \%$ of the zucchini samples were without residue and $20 \%$ were with residue $<$ MRL [Table 1]. Cucumber sample showed detected insecticides were found to exceed the MRL and none of the fungicides detected exceeded the MRL. However, the concentration of acetamiprid was $0.078 \mathrm{mg} \mathrm{kg}^{-1}$ detected on cucumber sample was exceeded the MRLs which was $0.03 \mathrm{mg} \mathrm{kg}^{-1}$ and residues of carbofuran that exceeded the MRLs were also found in one sample of cucumber and its concentration was $0.026 \mathrm{mg} \mathrm{kg}-1$.

\section{Evaluation of pesticide residue in tomatoes}

All tomato samples of supermarket were tested and it was found that all samples were having pesticides residue but the pesticides residue detected were below the MRL [Table 1]. Various types of pesticides were present in supermarket tomato. According to the detected pesticides, there are a wide range pesticides present in the tomato obtained from supermarket and farms including imidacloprid, acetamiprid, azoxystrobien, metalaxyland tolclofos, fenhexamid, panconazole and carbendazium [ Tables 2 and 3].

Table 1: Vegetable samples without pesticide residue and with residue $<M R L$ and $>M R L$.

\begin{tabular}{ccccc}
\hline Vegetables & No. of samples & Without residue & With residue $<$ MRL & With residue $>$ MRL \\
\hline Tomato & 10 & 0 & $10(100 \%)$ & 0 \\
Cucumber & 10 & $2(20 \%)$ & $6(60 \%)$ & $2(20 \%)$ \\
Zucchini & 10 & $8(80 \%)$ & $2(20 \%)$ & 0 \\
Pepper & 10 & $2(20 \%)$ & $8(80 \%)$ & 0 \\
Total & 40 & $12(30 \%)$ & $26(65 \%)$ & $2(5 \%)$ \\
\hline
\end{tabular}

Table 2: Various types of multi-residual pesticides in tomato samples of supermarket.

\begin{tabular}{|c|c|c|c|c|}
\hline Sample type & Sample & Observed pesticides & Conc. (ppm) & Mrls (eu) \\
\hline \multirow{15}{*}{ Tomato } & \multirow{5}{*}{1} & Panconazole & 0.064 & 0.1 \\
\hline & & Imidacloprid & 0.137 & 0.5 \\
\hline & & Acetamiprid & 0.031 & 0.5 \\
\hline & & Tolclofos-methyl & 0.015 & 1 \\
\hline & & Imidacloprid & 0.214 & 0.5 \\
\hline & \multirow[t]{2}{*}{2} & Acetamiprid & 0.165 & 0.5 \\
\hline & & Fenhexamid & 0.021 & 2 \\
\hline & \multirow{3}{*}{3} & Imidacloprid & 0.181 & 0.5 \\
\hline & & Acetamiprid & 0.033 & 0.5 \\
\hline & & Imidacloprid & 0.008 & 0.5 \\
\hline & \multirow{3}{*}{4} & Acetamiprid & 0.0682 & 0.5 \\
\hline & & Metalaxyl & 0.017 & 0.2 \\
\hline & & Imidacloprid & 0.062 & 0.5 \\
\hline & \multirow[t]{2}{*}{5} & Acetamiprid & 0.041 & 0.5 \\
\hline & & Azoxystrobien & 0.0358 & 3 \\
\hline
\end{tabular}




\section{Evaluation of pesticide residue in cucumber}

In this study, the concentrations of 8 different pesticides were determined in 5 cucumbers each from supermarket and farms. Of the detected pesticides, these were kresoxim-methyl, acetamiprid, metalaxyl, bifenthrin, burpufezine, acetamiprid and fenhexamid. All detected pesticides from supermarket was below MRL. None of pesticides was found above MRL [Table 4].

Cucumber sample shows that $2(20 \%)$ of the detected insecticides were found to exceed the MRL and none of the fungicides detected exceeded the MRL. Moreover, 2 out of 5 of cucumber samples tested from farms contains pesticides residue including carbofuran and acetamiprid above the MRLs [Table5]. Only one sample was not detected any pesticide. 2 out of 5 samples showed pesticides residue below the MRLs. However, the concentration of acetamiprid was $0.078 \mathrm{mg} \mathrm{kg}^{-1}$ detected on cucumber sample was exceeded the MRLs which was $0.03 \mathrm{mg} \mathrm{kg}^{-1}$. Additionally, residues of carbofuran that exceeded the MRLs were also found in one sample of cucumber and its concentration was $0.026 \mathrm{mg}$ $\mathrm{kg}-1$ as compared to MRL which was $0.002 \mathrm{mg} \mathrm{kg}-1$.

\section{Evaluation by pesticide residue in zucchini}

The concentrations of different pesticides were determined in zucchini of super market and farms samples. A total 4 out of 5 of zucchini samples of supermarket sample was tested and only one sample was detected with pesticide residue and it was below the MRL [Table 6]. In the farm sample, only one sample contains pesticides such as imidacloprid but it was below the MRL [Table 7].

\section{Evaluation by pesticide residue in pepper}

A total of 4 out of 5 pepper samples tested from supermarket were showing pesticides residue. Only one sample was not detected of any type of pesticide. The entire observed pesticides residue was below the MRLs. The detected pesticides were imidacloprid, diazinon, metalaxyl, acetamiprid and azoxystrobien [Table 8].

All five samples of pepper from farms were processed for measurement of pesticides. A total of 4 samples showed pesticide and only one sample did not show any pesticide. All the pesticides residue detected were below the MRLs [Table 9].

\section{The level of pesticide residues}

The level of pesticide residues in 40 vegetables was determined. Pesticide residues were detected in 26 out of 40 samples $(65 \%)$ but below the MRLs. A total of 2 out of 40 samples (5\%) were above the MRLs. Moreover, total 12 out of 40 samples (30\%) were free from any pesticide residues as compared to the European Union Standards. In

Table 3: Multi-residual pesticides in tomato samples from farms.

\begin{tabular}{|c|c|c|c|c|}
\hline Sample Type & Sample & Observed Pesticides & Conc. (ppm) & MRLs (EU) \\
\hline \multirow{12}{*}{ Tomato } & \multirow{3}{*}{1} & Acetamiprid & 0.039 & 0.5 \\
\hline & & Imidacloprid & 0.062 & 0.5 \\
\hline & & Metalaxyl & 0.017 & 0.2 \\
\hline & \multirow[t]{2}{*}{2} & Acetamiprid & 0.104 & 0.5 \\
\hline & & Acetamiprid & 0.094 & 0.5 \\
\hline & \multirow{3}{*}{3} & Imidacloprid & 0.03 & 0.5 \\
\hline & & Carbendazium & 0.02 & 0.3 \\
\hline & & Acetamiprid & 0.072 & 0.5 \\
\hline & \multirow{3}{*}{4} & Imidacloprid & 0.183 & 0.5 \\
\hline & & Fenhexamid & 0.058 & 0.2 \\
\hline & & Imidacloprid & 0.312 & 0.5 \\
\hline & 5 & Acetamiprid & 0.0208 & 0.5 \\
\hline
\end{tabular}

Table 4: Results of the detection of multi-residual pesticides in Cucumber samples from supermarket.

\begin{tabular}{ccccc}
\hline Sample Type & Sample & Observed Pesticides & Conc. (ppm) & MRLs (EU) \\
\hline \multirow{4}{*}{ Cucumber } & 1 & ND & & \\
& 2 & Kresoxim-methyl & 0.01 & 0.05 \\
& 3 & Acetamiprid & 0.029 & 0.3 \\
& 4 & Metalaxyl & 0.086 & 0.5 \\
& & Bifenthrin & 0.01 & 0.01 \\
& \multirow{2}{*}{5} & Burpufezine & 0.131 & 1 \\
& Acetamiprid & 0.104 & 0.3 \\
& Metalaxyl & 0.028 & 0.5 \\
\hline
\end{tabular}

Table 5: Results of the detection of multi-residual pesticides in Cucumber samples from Farm.

\begin{tabular}{|c|c|c|c|c|}
\hline Sample Type & Sample & Observed Pesticides & Conc. (ppm) & MRLs (EU) \\
\hline \multirow{6}{*}{ Cucumber } & \multirow{2}{*}{1} & Acetamiprid & 0.018 & 0.3 \\
\hline & & Metalaxyl & 0.009 & 0.5 \\
\hline & 2 & Not detected & & \\
\hline & 3 & Fenhexamid & 0.0406 & 1 \\
\hline & 4 & Carbofuran & 0.026 & 0.002 \\
\hline & 5 & Acetamiprid & 0.078 & 0.03 \\
\hline
\end{tabular}


Table 6: Results of the detection of multi-residual pesticides in Zucchini samples from Supermarket.

\begin{tabular}{ccccc}
\hline Sample Type & Sample & Observed Pesticides & Conc. (ppm) & MRLs (EU) \\
\hline \multirow{4}{*}{ Zucchini } & 1 & ND & & \\
& 2 & ND & & \\
& 3 & ND & 0.289 & 1 \\
4 & Azoxystrobien & & \\
\hline
\end{tabular}

Table 7: Results of the detection of multi-residual pesticides in Zucchini samples from farms.

\begin{tabular}{ccccc}
\hline Sample Type & Sample & Observed Pesticides & Conc. (ppm) & MRLs (EU) \\
\hline \multirow{3}{*}{ Zucchini } & 1 & ND & & \\
& 2 & ND & & \\
& 3 & ND & & \\
& 5 & ND & 0.461 & 1 \\
\hline
\end{tabular}

Table 8: Results of the detection of multi-residual pesticides in Pepper samples from Supermarket.

\begin{tabular}{|c|c|c|c|c|}
\hline Sample Type & Sample & Observed Pesticides & Conc. (ppm) & MRLs (EU) \\
\hline \multirow{10}{*}{ Pepper } & 1 & Imidacloprid & 0.182 & 1 \\
\hline & 2 & Diazinon & 0.029 & 0.05 \\
\hline & 3 & ND & & \\
\hline & \multirow{4}{*}{4} & Imidacloprid & 0.021 & 1 \\
\hline & & Acetamiprid & 0.009 & 0.3 \\
\hline & & Metalaxyl & 0.048 & 0.5 \\
\hline & & Diazinon & 0.021 & 0.05 \\
\hline & \multirow{3}{*}{5} & Imidacloprid & 0.185 & 1 \\
\hline & & Acetamiprid & 0.128 & 0.3 \\
\hline & & Azoxystrobien & 0.147 & 0.3 \\
\hline
\end{tabular}

Table 9: Results of the detection of multi-residual pesticides in Pepper samples from Farms.

\begin{tabular}{ccccc}
\hline Sample Type & Code & Observed Pesticides & Conc. (ppm) & MRLs (EU) \\
\hline \multirow{5}{*}{ Pepper } & A4 & Carbendazium & 0.062 & 1 \\
& B4 & Acetamiprid & 0.068 & 0.3 \\
& C4 & Acetamiprid & 0.099 & 0.3 \\
& D4 & Imidacloprid & 0.089 & 1 \\
& E4 & Acetamiprid & 0.147 & 0.3 \\
\hline
\end{tabular}

all analyzed samples, 14 different pesticides were detected. Acetamiprid was the most commonly detected pesticides and it was 18 out of 40 samples followed by imidacloprid which was detected on 14 out of 40 samples. A single residue was detected in $32.5 \%$ of the samples, and two, three, and four residues were detected in $15 \%, 15 \%$, and $7.5 \%$ of the samples respectively.

\section{DISCUSSION}

Pesticides are commonly applied in agriculture to increase the yield and pest control and food consumption is one of the most common routes of pesticide exposure in consumers ${ }^{21-23}$. Many pesticides cause various types of pathogenesis such as acute toxicity, as well as sub lethal effects causing the endocrine disorders, sperm quality decline and reproductive development abnormalities ${ }^{24-27}$. Besides, pesticides may enter the body by various ways depending on species, metabolic peculiarities, as well as susceptibility to toxins ${ }^{28}$ and causes various types of diseases.

Qassim province of Saudi Arabia is considered to be an important agricultural area due to its fertile soil. This study shows the evidences of the presence of pesticide residues in vegetables samples and it was revealed that pesticide residues above the maximum residue limits (MRL) were detected in 5\% of the samples and $65 \%$ samples showed various types of pesticides, but level was below of Maximum Residual
Limits compared to the European Union Standards. Similarly, Ramadan et al, 2011 reported that $68.7 \%$ samples were found to contain a detectable amount of pesticide residue and $20.9 \%$ contained pesticide residues whose concentration exceeded the $\mathrm{MRLs}^{29}$. In another study, it was also evidences that pesticides present in vegetables above the maximum residue levels ${ }^{30}$ and various types of pesticides present in samples as multiple residues were present in $40 \%$ of the samples with two-four pesticides ${ }^{20}$.

According to the detected pesticides, there are a wide range of pesticides present including imidacloprid, acetamiprid, azoxystrobien, metalaxyland tolclofos, fenhexamid, panconazole and carbendazium. Of the pesticides, acetamiprid was the most detected one pesticides followed by imidacloprid. A study based on Majmaah province, Saudi Arabia reported multiple residues were detected in $27 \%$ of analysed samples and cypermethrin was the most detected residue ${ }^{31}$. This finding confirms previous study based on Kazakhstan that designated that tomato and cucumber samples contained pesticide residues in various samples $^{32}$.

Eight different types of pesticides were determined in cucumbers samples of supermarket and farms. The detected pesticides were kresoxim-methyl, acetamiprid, metalaxyl, bifenthrin, burpufezine, acetamiprid and fenhexamid. Moreover, all detected pesticides from 
supermarket was below MRL but cucumber sample from farms showed insecticides were found to exceed the MRL. However, the concentration of acetamiprid was $0.078 \mathrm{mg} \mathrm{kg}^{-1}$ detected on cucumber sample was exceeded the MRLs which was $0.03 \mathrm{mg} \mathrm{kg}^{-1}$ according to European Union Standards. Additionally, residues of carbofuran that exceeded the MRLs and its concentration was $0.026 \mathrm{mg} \mathrm{kg}-1$ as compared to MRL which was $0.002 \mathrm{mg} \mathrm{kg-1}$. A previous study reported that ethion and imidacloprid pesticides were high and the maximum residue levels (MRLs) of ethion and imidacloprid were more than that of codex standard level. Moreover, after one-day pesticide application, the levels of pesticides were decreased but still were higher than the $\mathrm{MRL}^{23}$. Kuwait based study reported that imidaclropid, a systemic neonicotinoid insecticide used to control various pests of fruits and vegetables and is the most commonly detected pesticides ${ }^{33}$.

In current study, it was found that 4 out of 5 of pepper samples tested from supermarket were showing pesticides residue. The entire observed pesticides residue was below the MRLs and the detected pesticides were imidacloprid, diazinon, metalaxyl, acetamiprid and azoxystrobien Moreover, total of 4 samples of farms showed pesticide and only one sample was not detected any pesticide and all the pesticides residue detected were below the MRL. Moreover, study result reported that $12.9 \%$ of green peppers contained at least one detectable residue, but the levels were below the EU legal limits ${ }^{34}$

The current study finding established that 14 different pesticides were detected and detected pesticides residues were 8 fungicides $(57.1 \%)$ and 6 insecticides $(42.8 \%)$. Acetamiprid is one of the main detectable residues for vegetables and occurred on the concentration range of $0.009-0.147 \mathrm{mg} \mathrm{kg}^{-1}$. Similarly, incidence of multiple residues was found in commodities. Of the tested commodities, $12.8 \%$ contained a single residue, $41.7 \%$ contained two residues, $10.4 \%$ contained three residues, and $3.79 \%$ contained four residues. The occurrence of multi-residue pesticide contamination in several commodities has also been described in previous studies ${ }^{35,36}$. Previous study evidences that different pesticides are used to protect the various types of crops against pests and diseases, mainly vegetable crops that are cultivated under greenhouse conditions $s^{37,38}$

\section{CONCLUSION}

The results of the study designated that majority of the tested vegetable samples were contaminated with different types pesticide residues, but level was below the Maximum Residual Limits. The results revealed that cucumber samples were contaminated with pesticide residues, with concentrations above the MRL. However, the concentration of acetamiprid and carbofuran was $0.078 \mathrm{mg} \mathrm{kg}^{-1}$ and $0.026 \mathrm{mg} \mathrm{kg}-1$ which was exceeded the MRLs in cucumber samples. According to the results, the most detected pesticides among the tested vegetables were acetamiprid and its high-level causes various types of pathogenesis. The contamination levels of pesticide residues specially of farms could be a public health problem because most of the tested vegetables except zucchini are used without cooking. Continuous pesticide residue monitoring system is needed for vegetables especially those cultivated under farms conditions.

\section{REFERENCES}

1. Bradl H. Heavy Metals in the Environment: Origin, Interaction and Remediation. (Vol. 6). London: Academic Press (2002).

2. He ZL, Yang XE, Stoffella PJ. Trace elements in agroecosystems and impacts on the environment. J Trace Elem Med Biol. 2005;19(2-3):125-40.

3. Nicolopoulou-Stamati P, Maipas S, Kotampasi C, Stamatis P, Hens L. Chemical pesticides and human health: the urgent need for a new concept in agriculture. Front Public Health. (2016) 4:148.

4. Hodgson E. Metabolism of pesticides. In: Krieger R, editor. Hayes' handbook of pesticide toxicology. 3rd ed. New York: Academic Press; 2010. pp. 893-921
5. Colborn T. A case for revisiting the safety of pesticides: a closer look at neurodevelopment. Environ Health Perspect. 2006;114:10-17.

6. Eriksson P, Talts U. Neonatal exposure to neurotoxic pesticides increases adult susceptibility: a review of current findings. Neurotoxicology. 2000;21:37-47.

7. Eskenazi B, Bradman A, Castorina R. Exposures of children to organophosphate pesticides and their potential adverse health effects. Environ Health Perspect. 1999;107(Suppl 3):409-19.

8. Eskenazi B, Rosas LG, Marks AR, Bradman A, Harley K, Holland N, Johnson C, Fenster L, Barr DB. Pesticide toxicity and the developing brain. Basic Clin Pharmacol Toxicol. 2008;102:228-36.

9. Liu B, Gao HM, Hong JS. Parkinson's disease and exposure to infectious agents and pesticides and the occurrence of brain injuries: role of neuroinflammation. Environ Health Perspect. 2003;111:1065-73.

10. Weiss B. Vulnerability to pesticide neurotoxicity is a lifetime issue. Neurotoxicology. 2000;21:67-73.

11. EFSA (2010). 2008 Annual report on pesticide residues according to article 32 of regulation(EC) No 396/2005. EFSA Journal. 8(6), 1646.

12. Pengyan L, Quingxue L, Yusong M, Jinwei L, Xuan J, Chin J. Analysis of pesticide multiresidues in rice by gas chromatography-mass spectrometry coupled with solid phase extraction. J. Chromatogr. A. 2006;24:228-38.

13. Libin L, Hashi Y, Yaping Q, Haixia Z, Jinming L. Rapid analysis of multiresidual pesticides in agricultural products by gas chromatography-mass spectrometry. $\mathrm{J}$. Anal. Chem. 2006;34:783-6.

14. Nguyen TD, Lee B S, Lee BR, Lee DM, Lee GH. multiresidue method for the determination of 109 pesticides in rice using the quick easy cheap effective rugged and safe (QuEChERS) sample preparation method and gas chromatography/mass spectrometry with temperature control and vacuum concentration. Rapid Commun. Mass Spectrom. 2007;21:3115-22.

15. Liu LB, Hashi Y, Qin YP. Mass spectrometry for measuring multiresidual pesticides in agricultural products. J. Chromatogr. B. 2007;845:61-8.

16. Hajslova J, Zrostlikova J. Matrix effects in (ultra) trace analysis of pesticide residues in food and biotic matrices. J. Chromatogr. A. 2003;1000:181-97.

17. Anastassiades, M., Lehotay, S. J., Stajnbaher, D., and Schenck, F. J. (2003) Fast and easy multiresidue method employing acetonitrile extraction/partitioning and 'dispersive solid-phase extraction' for the determination of pesticide residues in produce, J. AOAC Int. 86, 412-431.

18. M. Dušek, V. Jandovská, and J. Olšovská, "Analysis of multiresidue pesticides in dried hops by LC-MS/MS using QuEChERS extraction together with dSPE clean-up," Journal of the Institute of Brewing, vol. 124, no. 3, pp. 222-229, 2018.

19. European Commission. Establishing Community Methods of Sampling for the Official Control of Pesticide Residues in and on Products of Plant and Animal Origin and Repealing Directive. OJEU L 2002, 187, 30-43.

20. Jallow, M.F.; Awadh, D.G.; Albaho, M.S.; Devi, V.Y.; Ahmad, N. Monitoring of pesticide residues in commonly used fruits and vegetables in Kuwait. Int. J. Environ. Res. Public Health 2017, 14, 833.

21. Shokrzadeh M, Saberyan M, Saeedi Saravi S. (2008). Assessment of lead (Pb) and cadmium $(\mathrm{Cd})$ in 10 samples of Iranian and foreign consumed tea leaves and dissolved beverages. Toxicol Environ Chem, 90(5):879-83.

22. Carvalho FP. (2006). Agriculture, pesticides, food security and food safety. Environ Sci Policy, 9( 7-8): 685-92.

23. Leili M, Pirmoghani A, Samadi MT, Shokoohi R, Roshanaei G, Poormohammad A. Determination of pesticides residues in cucumbers grown in greenhouse and the effect of some procedures on their residues. Iran J Public Health. 2016;45:1481-90.

24. Pretali L, Bernardo L, Butterfield TS, Trevisan M, Lucini L. Botanical and biological pesticides elicit a similar induced systemic response in tomato (Solanum lycopersicum) secondary metabolism. Phytochemistry. 2016;130:5663.

25. Mahboob S, Niazi F, Alghanim K, Sultana S, Almisned F, Ahmed Z. Health risks associated with pesticide residues in water, sediments and the muscle tissues of Catla Catla at head Balloki on the river Ravi. Environ Monit Assess. 2015;187:81.

26. Cremonese C, Piccoli C, Pasqualotto F, Clapauch R, Koifman RJ, Koifman S, et al. Occupational exposure to pesticides, reproductive hormone levels and sperm quality in young Brazilian men. Reprod Toxicol. 2017;67:174-85

27. Clara V, Nieto R, Rosa M, Nadia B, Victoria LL, Horacio $R$, et al. Pesticide chlorpyrifos acts as an endocrine disruptor in adult rats causing changes in mammary gland and hormonal balance. J Steroid Biochem Mol Biol. 2015;156:1-9.

28. Hodgson E. Metabolism of pesticides. In: Krieger R, editor. Hayes' handbook of pesticide toxicology. 3rd ed. New York: Academic Press; 2010. pp. 893-921.

29. Ramadan MFA, Abdel-Hamid MMA, Altorgoman MMF, et al. Evaluation of Pesticide Residues in Vegetables from the Asir Region, Saudi Arabia. Molecules. 2020;25(1):205 
30. Osman, K.A.; Al-Humaid, A.M.; Al-Rehiayani, S.M.; Al-Redhaiman, K.N. Monitoring of pesticide residues in vegetables marketed in Al-Qassim region, Saudi Arabia. Ecotoxicol. Environ. Saf. 2010;73:1433-9.

31. Abd-Elhaleem, Z.A. Pesticide residues in tomato and tomato products marketed in Majmaah province, KSA, and their impact on human health. Environ Sci Pollut Res 27, 8526-8534 (2020)

32. Lozowicka B, Abzeitova E, Sagitov A, Kaczynski P, Toleubayev K, Li A. (2015) Studies of pesticide residues in tomatoes and cucumbers from Kazakhstan and the associated health risks. Environmental Monitoring and Assessment. 187(10).

33. Mustapha F. A. Jallow, Dawood G. Awadh, Mohammed S. Albaho, Vimala Y Deviand Nisar Ahmad. (2017). Monitoring of Pesticide Residues in Commonly Used Fruits and Vegetables in Kuwait. Int J Environ Res Public Health. 14(8):833.

34. Golge O, Hepsag F, Kabak B. Health risk assessment of selected pesticide residues in green pepper and cucumber. Food Chem Toxicol. 2018:121:51-64.
35. Allen, G.; Halsall, C.J.; Ukpebor, J.; Paul, N.D.; Ridall, G.; Jason, J.; Wargent, J.J. Increased occurrence of pesticide residues on crops grown in protected environments compared to crops grown in open field conditions. Chemosphere 2015, 119,1428-35.

36. Osman, K.A.: Al-Humaid, A.I.: Al-Rehiayani, S.M.: Al-Redhaiman, K.N. Estimated daily intake of pesticide residues exposure by vegetables grown in greenhouses in Al-Qassim region, Saudi Arabia. Food Control 2011, 22, 947953.

37. Paradjikovic, N.; Hrlec, G.; Horvat, D. Residues of vinclozolin and procymidone after treatment of greenhouse grown lettuce, tomato and cucumber. Acta Agric. Scand. Sect. B Soil Plant Sci. 2004, 54, 241-248.

38. Li, W.; Tai, L.; Liu, J.; Gai, Z.; Ding, G. Monitoring of pesticide residues levels in fresh vegetable form Heibei Province, North China. Environ. Monit. Assess. 2014, 186, 6341-6349.

\section{GRAPHICAL ABSTRACT}

\section{Pesticide Residue Measurement in Commonly Used Vegetables Using the QuEChERS Method}

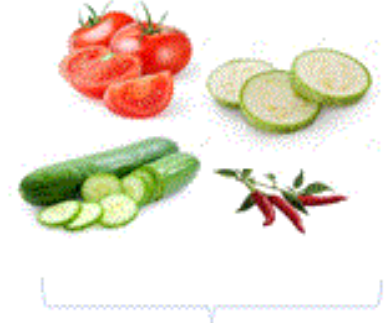

Extraction by using QuEChERS Method

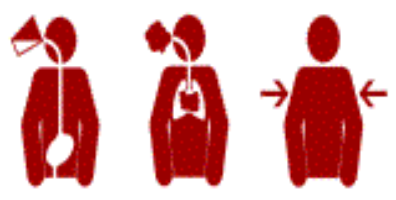

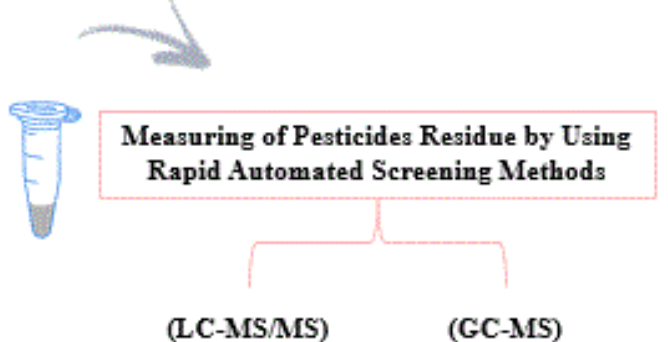

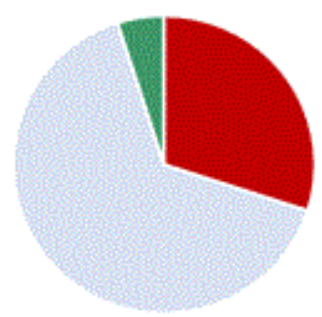

- Without residue $\Rightarrow$ With residne $<$ MRL $=$ With residne $>$ MRI

\section{ABOUT AUTHORS}

Waad H. AISaikhan: is a medical laboratory specialist graduated from the Department of Medical Laboratories, College of Applied Medical Sciences, Qassim University, Kingdom of Saudi Arabia. Her research areas are measurement of pesticides residue in vegetables/ fruits and medical laboratory science in general. She has presented research work based on pesticides in national conference.

Saleh A. Almatroodi: Is a researcher and an assistant professor in laboratory medicine at Qassim University. He is the Vice Dean of College of Applied Medical Science and the head of E-learning unit in College of Applied Medical Sciences, Qassim University, Kingdom of Saudi Arabia. His research interests include evaluation of the therapeutic potential of natural compounds in the management of diseases including cancer. He has published several meaningful research papers in international repute journal and has presented his papers in many national and international conferences. 
Ahmad Almatroudi Is working as an Assistant Professor in the Department of Medical Laboratories, College of Applied Medical Sciences, Qassim University, Kingdom of Saudi Arabia. His research interests include measurement of the therapeutic potential of natural compounds in the management of diseases, Public health and Microbiology. Ahmad Almatroudi is currently chairman of Department of Medical Laboratories. He has published several meaningful research and review article, of international repute journal and has presented his papers in many national and international conferences.

Mohammed A. Alsahli: Is an Assistant Professor in Medical Laboratory Sciences at Qassim University. His research interests involve medical laboratory sciences in general, particularly oncology, platelet biology and haemostatic regulation in prothrombotic diseases. Mohammed is currently the Dean of College of Applied Medical Sciences, Qassim University, Saudi Arabia. He has published several research and review article, of international repute journal.

Arshad Husain Rahmani: Is working as an Assistant Professor in the Department of Medical Laboratories, College of Applied Medical Sciences, Qassim University, Kingdom of Saudi Arabia. His research interests include measurement of the therapeutic potential of natural compounds in the management of diseases and expression pattern of the genes linked to cancer development and progression. He has published more than 80 research and review article, of international repute. Besides this, he is an active reviewer of several ISI indexed journals.

Cite this article: Alsaikhan WH, Almatroodi SA, Almatroudi A, Alsahli MA, Rahmani AH. Pesticide Residue Measurement in Commonly Used Vegetables Using the QuEChERS Method. Pharmacog J. 2021;13(1): 142-9. 